\title{
openheart Supplemental N-acetylcysteine and other measures that boost intracellular glutathione can downregulate interleukin-1 $\beta$ signalling: a potential strategy for preventing cardiovascular events?
}

\author{
James J DiNicolantonio, ${ }^{1}$ James H O’Keefe, ${ }^{1}$ Mark F McCarty ${ }^{2}$
}

\section{To cite:}

DiNicolantonio JJ, O'Keefe JH, McCarty MF. Supplemental $\mathrm{N}$-acetylcysteine and other measures that boost intracellular glutathione can downregulate interleukin-1 $\beta$ signalling: a potential strategy for preventing cardiovascular events?. Open Heart 2017;4:e000599. doi:10.1136/ openhrt-2017-000599

Accepted 13 July 2017

\section{CrossMark}

${ }^{1}$ Saint Luke's Mid America Heart Institute, Kansas, USA

${ }^{2}$ Catalytic Longevity, Encinitas, California, USA

Correspondence to Dr James J DiNicolantonio, Saint Luke's Mid America Heart Institute, Kansas, M0 64111, USA; jjdinicol@gmail.com
INTERLEUKIN-1 —LIKELY MEDIATOR OF CRPASSOCIATED CARDIOVASCULAR RISK

A proinflammatory milieu associated with elevations of C-reactive protein (CRP) and homocysteine has been linked epidemiologically to increased risk for myocardial infarction (MI). Nonetheless, there is good reason to suspect that neither CRP nor homocysteine are mediators of this risk, but rather serve as markers for increased activity of another agent or agents that are true mediators. ${ }^{1-4}$ The search for such a mediator has cast suspicion on interleukin (IL)-1 $\beta$, which, in conjunction with IL-6, boosts hepatic expression of CRP. ${ }^{5}{ }^{6}$ While the effects of IL-1 $\beta$ on hepatic acute phase protein expression are variable, IL-1 $\beta$ also promotes hepatic synthesis of serum amyloid A, another acute phase reactant linked to increased cardiovascular (CV) risk. ${ }^{57}$ Furthermore, there is some reason to suspect that IL-1 $\beta$ may act on the liver to boost homocysteine levels. ${ }^{8}$ Rodent and cell culture studies indicate that IL-1 $\beta$ can promote atherogenesis by via effects on endothelial, smooth muscle and foam cells. ${ }^{9-16}$ Conversely, apolipoprotein E knockout mice in which IL-1 $\beta$ has likewise been knocked out, or that are treated with a monoclonal antibody targeting IL-1 $\beta$, are less prone to atherogenesis. ${ }^{17-19}$ The impact of canakinumab, a monoclonal antibody targeting IL-1 $\beta$, is now being studied for secondary prevention of MI in patients with elevated CRP in the Canakinumab Anti-inflammatory Thrombosis Outcomes Study (CANTOS) multicenter trial. ${ }^{20}$ This trial should provide important insight regarding the suspected role of IL-1 $\beta$ in coronary events. A pilot study has already confirmed that canakinumab can markedly lower elevated CRP; its impact on homocysteine has not yet been evaluated. ${ }^{21}$ The ability of potent statin therapy to decrease risk for coronary events in patients with elevated CRP but low-normal low density lipoprotein (LDL) cholesterol might reflect a suppressive impact of statins on IL-1 $\beta$ activation via inflammasomes. ${ }^{22-25}$ While canakinumab may prove to be an important therapeutic asset for patients with established coronary disease, the availability of IL-1 $\beta$-antagonist measures that are less expensive and more practical for use in primary prevention of atherosclerotic disorders would be welcome.

\section{ROLE OF NEUTRAL SPHINGOMYELINASE IN SUSTAINED IL-1 SIGNALLING}

Recent studies, employing rat primary hepatocytes as well as a human embryonic kidney cell line transfected with the IL-1 $\beta$ receptor, have defined a feed-forward mechanism that controls the intensity of IL- $1 \beta$ signalling. IL-1 receptor associated kinase-1 (IRAK-1) is an obligate mediator of this signalling, a key component of the complex formed with the activated IL-1 $\beta$ receptor, and its level is a determinant of the intensity of IL-1 $\beta$ signalling. ${ }^{26}$ When IRAK- 1 is phosphorylated by IRAK-4, another member of this complex, its kinase activity is enabled; IRAK-1-mediated phosphorylations then lead to transmission of the IL-1 $\beta$ signal, with downstream activation of transforming growth factor beta-activated kinase 1 (TAK1), c-Jun N-terminal kinases (JNK) and nuclear 
factor kappa-light-chain-enhancer of activated B cells $(\mathrm{NF}-\mathrm{KB}) .{ }^{27-29}$ However, IRAK-1 also autophosphorylates certain serine/threonine residues in its C-terminal region, and some of these phosphorylations enable polyubiquitination and subsequent proteasomal degradation of the protein. ${ }^{26}$ For this reason, the strength of the IL- $1 \beta$ signal tends to fade over time.

One downstream effect of IL-1 $\beta$ signalling is activation of neutral sphingomyelinase 2 (NSMase-2), leading to generation of ceramide. ${ }^{30}$ Ceramide, in turn, binds and activates protein phosphatase 2A (PP2A), which dephosphorylates IRAK-1 in such a manner as to protect it from ubiquitination and proteasomal degradation. ${ }^{31}{ }^{32}$ Hence, this arm of the IL-1 $\beta$ signalling network functions to sustain the intensity of the IL- $1 \beta$ signal.

However, NSMase-2 is subject to redox regulation, as it is inhibited by free glutathione in physiological millimolar concentrations. ${ }^{33} 34$ This inhibition blunts the generation of ceramide induced by IL- $1 \beta$ activity, leading to accelerated degradation of IRAK-1 and downregulation of the IL-1 $\beta$ signal. ${ }^{32} 35$ It follows that measures which boost cellular levels of glutathione can suppress, though not eliminate, IL-1 $\beta$ signalling. (Such signalling would continue with diminished intensity, as IRAK-1 levels would be decreased but not eliminated.)

\section{BOOSTING CELLULAR GLUTATHIONE LEVELS DOWNREGULATES IL-1 SIGNALLING}

Glutathione, present in low millimolar concentrations in most cells, constitutes the chief water-soluble intracellular oxidant scavenger, protecting the membranes, DNA and proteins of oxidatively stressed tissues. (Ascorbate is likewise of importance in this regard.) It also opposes the proinflammatory/proapoptotic signalling effects of hydrogen peroxide, both by enabling the degradation of this compound via glutathione peroxidase and by working with glutaredoxin to promote the restoration of sulfenic acids to sulfhydryl form. ${ }^{36-40}$ As we have seen, it can also oppose IL-1 $\beta$-induced inflammation via its inhibitory impact on NSMase-2. A further role of glutathione is to aid excretion of relatively hydrophobic compounds via conjugation reactions catalysed by glutathione-S-transferases. $^{41}$

Intracellular cysteine availability is rate limiting for glutathione synthesis, such that increased cysteine levels boost this synthesis. ${ }^{42} \mathrm{~N}$-acetylcysteine (NAC) is a venerable nutraceutical which acts as a well-tolerated delivery vehicle for cysteine when administered orally. Both rodent and clinical studies show that NAC supplementation can boost tissue glutathione levels; the clinical doses employed have usually been in the range of 600-1800 mg daily. ${ }^{43} 44$ NAC supplementation may have particular utility in the elderly, as a decline in tissue glutathione levels is a characteristic feature of ageing; nonetheless, these levels can be boosted by NAC supplementation or a diet richer in cysteine. ${ }^{45-48}$ In vitro, as expected, NAC treatment has been shown to blunt the intensity of IL-1 $\beta$ signalling in hepatocytes from ageing rats by promoting degradation of IRAK- $1 .{ }^{49}$

If clinical administration of NAC can indeed antagonise IL-1 $\beta$ signalling, and if CRP serves as a marker for hepatic IL-1 $\beta$ activity, one would expect supplemental NAC to decrease elevated CRP levels. Indeed, several studies evaluating intravenous or oral NAC administration in various proinflammatory conditions have demonstrated precisely this. $^{50-53}$

The other key determinant of the rate of glutathione synthesis is the expression of gamma-glutamylcysteine synthetase, a phase 2 enzyme whose transcription is stimulated by activation of the nuclear factor (erythroid-derived 2)-like 2 (nrf2) transcription factor. ${ }^{54}{ }^{55} \mathrm{~A}$ wide range of nutraceuticals and drugs, characterised as 'phase 2 inducers', are known to activate nrf2, leading to induction of a range of antioxidant enzymes, as well as gamma-glutamylcysteine synthetase. Perhaps, the most clinically developed of these is the natural cofactor lipoic acid (transported most effectively as its natural R-isomer ${ }^{56}$ ), which has documented clinical utility in diabetic neuropathy when administered at $1200-1800 \mathrm{mg}$ daily-a clinical dose range similar to that of NAC. ${ }^{45} 57-5$ ${ }^{9}$ In ageing rats, oral administration of R-lipoic acid has been shown to boost myocardial glutathione levels, while decreasing those of ceramide ${ }^{60}$ - an effect likely attributable to inhibition of NSMase-2. Lipoic acid has likewise been shown to diminish ceramide levels and the activities of NSMase-2 and PP2A in endothelial cells in vitro. ${ }^{61}$

Since free, rather than oxidised, glutathione inhibits NSMase-2; it follows that the rate of intracellular generation of hydrogen peroxide-which promotes the oxidative conversion of glutathione to diglutathione-can also modulate NSMase-2 activity. Hence, rapid intracellular production of superoxide, which yields hydrogen peroxide after its dismutation, tends to elevate NSMase-2 activity and the intensity of IL-1 $\beta$ signalling. ${ }^{62-65}$ Hence, practical measures which quell superoxide generation by NADPH oxidase complexes, mitochondria or uncoupled nitric oxide synthase may have potential for downregulating IL-1 $\beta$ signalling in certain clinical circumstances.

\section{OXIDATIVE STRESS AND INFLAMIMASOME ACTIVATION}

Consideration should also be given to the possibility that NAC and other antioxidant strategies might decrease production of IL-1 $\beta$ by limiting inflammasome activation. Inflammasomes featuring the protein NLRP3 play an obligate role in generation of IL-1 $\beta$; they activate caspase-1, which cleaves the pro-IL-1 $\beta$ protein to yield mature IL-1 $\beta .{ }^{66}$ Oxidative stress can activate NLR Family Pyrin Domain Containing 3 (NLRP3)-dependent inflammasomes, apparently by inducing increased expression of the thioredoxin-interacting protein (TXNIP), which binds to NLRP3; oxidants also increase the availability of free TXNIP by inhibiting its binding to thioredoxin. ${ }^{67-69}$ A number of studies show that oxidants generated by NADPH oxidase complexes can promote activation of 
NLRP3-dependent inflammasomes. ${ }^{70-73}$ The fact that statins can downregulate NADPH oxidase activation by suppressing isoprenylation of Rac1 may well be pertinent to the ability of these drugs to decrease inflammasome activity and decrease IL-1 $\beta$ production. ${ }^{74-76}$ Free intracellular bilirubin generated by haeme oxygenase-1 induction functions physiologically as an inhibitor of NADPH oxidase complexes, and the structurally-related compound phycocyanobilin, a prominent chromophore in edible cyanobacteria such as spirulina, appears to mimic this activity; this natural compound may thus have potential for suppressing inflammasome activation and IL-1 $\beta$ production. ${ }^{77-81}$ In a large number of cell culture studies, NAC has been reported to inhibit inflammasome activation and IL-1 $\beta$ production. ${ }^{82-88}$ However, these studies do not clarify whether increased glutathione mediates this effect or whether the direct scavenging activity of NAC does; in the latter case, these effects might be of limited clinical relevance. Further research to clarify this point could be worthwhile. Many cell signalling effects of oxidative stress reflect hydrogen peroxide-mediated oxidation of protein sulfhydryl groups to sulfenic acid; glutathione functions to reverse this modification. ${ }^{38-40}$ Glutathione also promotes elimination of hydrogen peroxide via glutathione peroxidase. ${ }^{37}$

\section{SUMIMING UP}

In the event that the ongoing CANTOS study confirms that IL-1 $\beta$ is an important mediator of CV disease, measures in addition to canakinumab for downregulating the signalling and production of IL-1 $\beta$ should be evaluated. The impact of high-dose rosuvastatin on elevated CRP suggests that it may be suppressing IL- $1 \beta$ production, and there is reason to suspect that NAC, lipoic acid and phycocyanobilin may have practical potential as nutraceutical measures for controlling IL-1 $\beta$ activity.

Contributors All authors contributed to the final manuscript.

Competing interests JJD is the author of The Salt Fix and has a website thesaltfix.com. JOK and MFM own nutraceutical companies.

Provenance and peer review Not commissioned; externally peer reviewed.

Open Access This is an Open Access article distributed in accordance with the Creative Commons Attribution Non Commercial (CC BY-NC 4.0) license, which permits others to distribute, remix, adapt, build upon this work non-commercially, and license their derivative works on different terms, provided the original work is properly cited and the use is non-commercial. See: http://creativecommons.org/ licenses/by-nc/4.0/

(c) Article author(s) (or their employer(s) unless otherwise stated in the text of the article) 2017. All rights reserved. No commercial use is permitted unless otherwise expressly granted.

\section{REFERENCES}

1. Casas JP, Shah T, Cooper J, et al. Insight into the nature of the CRPcoronary event association using Mendelian randomization. Int $J$ Epidemiol 2006;35:922-31.

2. Wensley F, Gao P, Burgess S, et al. Association between $\mathrm{C}$ reactive protein and coronary heart disease: mendelian randomisation analysis based on individual participant data. BMJ 2011;342:d548.

3. Marti-Carvajal AJ, Sola I, Lathyris D, et al. Homocysteine lowering interventions for preventing cardiovascular events. Cochrane Database Syst Rev 2009:CD006612.
4. Yang HT, Lee M, Hong KS, et al. Efficacy of folic acid supplementation in cardiovascular disease prevention: an updated meta-analysis of randomized controlled trials. Eur J Intern Med 2012;23:745-54.

5. Bode JG, Albrecht U, Häussinger D, et al. Hepatic acute phase proteins--regulation by IL-6- and IL-1-type cytokines involving STAT3 and its crosstalk with NF-кB-dependent signaling. Eur J Cell Biol 2012;91:496-505.

6. Ridker PM. From C-reactive protein to interleukin-6 to interleukin-1: moving upstream to identify novel targets for atheroprotection. Circ Res 2016;118:145-56.

7. Johnson BD, Kip KE, Marroquin OC, et al. Serum amyloid A as a predictor of coronary artery disease and cardiovascular outcome in women: the National Heart, Lung, and Blood Institute-Sponsored Women's Ischemia Syndrome Evaluation (WISE). Circulation 2004;109:726-32.

8. McCarty MF, O'Keefe JH, Di Nicolantonio JJ, et al. Interleukin-1 beta may act on hepatocytes to boost plasma homocysteine the increased cardiovascular risk associated with elevated homocysteine may be mediated by this cytokine. Med Hypotheses 2017;102:78-81.

9. Bevilacqua MP, Pober JS, Wheeler ME, et al. Interleukin-1 activation of vascular endothelium. effects on procoagulant activity and leukocyte adhesion. Am J Pathol 1985;121:394-403.

10. Lisinski TJ, Furie MB. Interleukin-10 inhibits proinflammatory activation of endothelium in response to Borrelia burgdorferi or lipopolysaccharide but not interleukin-1beta or tumor necrosis factor alpha. J Leukoc Biol 2002;72:503-11.

11. Vallejo S, Palacios E, Romacho T, et al. The interleukin-1 receptor antagonist Anakinra improves endothelial dysfunction in streptozotocin-induced diabetic rats. Cardiovasc Diabetol 2014;13:158.

12. Bonin PD, Fici GJ, Singh JP, et al. Interleukin-1 promotes proliferation of vascular smooth muscle cells in coordination with PDGF or a monocyte derived growth factor. Exp Cell Res 1989;181:475-82.

13. Yoon J, Ryoo S. Arginase inhibition reduces interleukin-1 $\beta$-stimulated vascular smooth muscle cell proliferation by increasing nitric oxide synthase-dependent nitric oxide production. Biochem Biophys Res Commun 2013;435:428-33.

14. Eun SY, Ko YS, Park SW, et al. IL-1 $\beta$ enhances vascular smooth muscle cell proliferation and migration via $\mathrm{P} 2 \mathrm{Y} 2$ receptor-mediated RAGE expression and HMGB1 release. Vascul Pharmacol 2015;72:108-17.

15. Shimokawa $\mathrm{H}$, Ito $A$, Fukumoto $Y$, et al. Chronic treatment with interleukin-1 beta induces coronary intimal lesions and vasospastic responses in pigs in vivo. the role of platelet-derived growth factor. $J$ Clin Invest 1996;97:769-76.

16. Liu W, Yin Y, Zhou Z, et al. OxLDL-induced IL-1 beta secretion promoting foam cells formation was mainly via CD36 mediated ROS production leading to NLRP3 inflammasome activation. Inflamm Res 2014;63:33-43.

17. Kirii H, Niwa T, Yamada Y, et al. Lack of interleukin-1beta decreases the severity of atherosclerosis in ApoE-deficient mice. Arterioscler Thromb Vasc Biol 2003;23:656-60.

18. Kamari $Y$, Shaish A, Shemesh S, et al. Reduced atherosclerosis and inflammatory cytokines in apolipoprotein-E-deficient mice lacking bone marrow-derived interleukin-1 $\alpha$. Biochem Biophys Res Commun 2011:405:197-203.

19. Bhaskar V, Yin J, Mirza AM, et al. Monoclonal antibodies targeting $\mathrm{IL}-1$ beta reduce biomarkers of atherosclerosis in vitro and inhibit atherosclerotic plaque formation in apolipoprotein E-deficient mice. Atherosclerosis 2011;216:313-20.

20. Ridker PM, Thuren T, Zalewski A, et al. Interleukin-1ß inhibition and the prevention of recurrent cardiovascular events: rationale and design of the Canakinumab Anti-inflammatory Thrombosis Outcomes Study (CANTOS). Am Heart J 2011;162:597-605.

21. Ridker PM, Howard CP, Walter V, et al. Effects of interleukin-1 $\beta$ inhibition with canakinumab on hemoglobin A1c, lipids, C-reactive protein, interleukin-6, and fibrinogen: a phase IIb randomized, placebo-controlled trial. Circulation 2012;126:2739-48.

22. Ridker PM, Danielson E, Fonseca FA, et al. Rosuvastatin to prevent vascular events in men and women with elevated C-reactive protein. N Engl J Med 2008;359:2195-207.

23. Altaf $A, Q u P$, Zhao $Y$, et al. NLRP3 inflammasome in peripheral blood monocytes of acute coronary syndrome patients and its relationship with statins. Coron Artery Dis 2015;26:409-21.

24. Satoh $M$, Tabuchi $T$, Itoh $T$, et al. NLRP3 inflammasome activation in coronary artery disease: results from prospective and randomized study of treatment with atorvastatin or rosuvastatin. Clin Sci 2014;126:233-41. 
25. Luo B, Li B, Wang W, et al. Rosuvastatin alleviates diabetic cardiomyopathy by inhibiting NLRP3 inflammasome and MAPK pathways in a type 2 diabetes rat model. Cardiovasc Drugs Ther 2014;28:33-43.

26. Yamin TT, Miller DK. The interleukin-1 receptor-associated kinase is degraded by proteasomes following its phosphorylation. $\mathrm{J} \mathrm{Biol}$ Chem 1997;272:21540-7

27. Li S, Strelow A, Fontana EJ, et al. IRAK-4: a novel member of the IRAK family with the properties of an IRAK-kinase. Proc Natl Acad Sci U S A 2002;99:5567-72.

28. Ninomiya-Tsuji J, Kishimoto K, Hiyama A, et al. The kinase TAK1 can activate the NIK-I kappaB as well as the MAP kinase cascade in the IL-1 signalling pathway. Nature 1999;398:252-6.

29. Hammaker DR, Boyle DL, Inoue T, et al. Regulation of the JNK pathway by TGF-beta activated kinase 1 in rheumatoid arthritis synoviocytes. Arthritis Res Ther 2007;9:R57.

30. Karakashian AA, Giltiay NV, Smith GM, et al. Expression of neutral sphingomyelinase-2 (NSMase-2) in primary rat hepatocytes modulates IL-beta-induced JNK activation. FASEB J 2004;18:968-70.

31. Dobrowsky RT, Kamibayashi C, Mumby MC, et al. Ceramide activates heterotrimeric protein phosphatase 2A. J Biol Chem 1993;268:15523-30.

32. Dobierzewska A, Giltiay NV, Sabapathi S, et al. Protein phosphatase $2 \mathrm{~A}$ and neutral sphingomyelinase 2 regulate IRAK-1 protein ubiquitination and degradation in response to interleukin-1beta. $J$ Biol Chem 2011;286:32064-73.

33. Liu B, Hannun YA. Inhibition of the neutral magnesium-dependent sphingomyelinase by glutathione. J Biol Chem 1997;272:16281-7.

34. Liu B, Andrieu-Abadie N, Levade T, et al. Glutathione regulation of neutral sphingomyelinase in tumor necrosis factor-alpha-induced cell death. J Biol Chem 1998;273:11313-20.

35. Rutkute K, Asmis RH, Nikolova-Karakashian MN, et al. Regulation of neutral sphingomyelinase-2 by GSH: a new insight to the role of oxidative stress in aging-associated inflammation. J Lipid Res 2007;48:2443-52.

36. Lo Conte M, Carroll KS. The redox biochemistry of protein sulfenylation and sulfinylation. J Biol Chem 2013;288:26480-8.

37. Arthur JR. The glutathione peroxidases. Cell Mol Life Sci 2000;57:1825-35.

38. Dickinson DA, Forman HJ. Glutathione in defense and signaling: lessons from a small thiol. Ann N Y Acad Sci 2002;973:488-504.

39. Shelton MD, Chock PB, Mieyal JJ, et al. Glutaredoxin: role in reversible protein s-glutathionylation and regulation of redox signal transduction and protein translocation. Antioxid Redox Signal 2005;7:348-66.

40. Parsons ZD, Gates KS. Thiol-dependent recovery of catalytic activity from oxidized protein tyrosine phosphatases. Biochemistry 2013;52:6412-23.

41. Rushmore TH, Pickett CB. Glutathione S-transferases, structure, regulation, and therapeutic implications. J Biol Chem 1993;268:11475-8.

42. Richman PG, Meister A. Regulation of gamma-glutamyl-cysteine synthetase by nonallosteric feedback inhibition by glutathione. J Biol Chem 1975;250:1422-6.

43. Atkuri KR, Mantovani JJ, Herzenberg LA, et al. N-acetylcysteine - a safe antidote for cysteine/glutathione deficiency. Curr Opin Pharmacol 2007;7:355-9.

44. Dodd S, Dean O, Copolov DL, et al. N-acetylcysteine for antioxidant therapy: pharmacology and clinical utility. Expert Opin Biol Ther 2008;8:1955-62

45. Suh JH, Wang H, Liu RM, et al. (R)-alpha-lipoic acid reverses the age-related loss in GSH redox status in post-mitotic tissues: evidence for increased cysteine requirement for GSH synthesis. Arch Biochem Biophys 2004;423:126-35.

46. Dröge W, Kinscherf R, Hildebrandt W, et al. The deficit in low molecular weight thiols as a target for antiageing therapy. Curr Drug Targets 2006;7:1505-12.

47. Sekhar RV, Patel SG, Guthikonda AP, et al. Deficient synthesis of glutathione underlies oxidative stress in aging and can be corrected by dietary cysteine and glycine supplementation. Am J Clin Nutr 2011:94:847-53.

48. Dröge W. Oxidative stress and ageing: is ageing a cysteine deficiency syndrome? Philos Trans $R$ Soc Lond B Biol Sci 2005;360:2355-72.

49. Kerstetter JE, Looker AC, Insogna KL, et al. Low dietary protein and low bone density. Calcif Tissue Int 2000;66:313.

50. Kudaravalli J. Improvement in endothelial dysfunction in patients with systemic lupus erythematosus with $\mathrm{N}$-acetylcysteine and atorvastatin. Indian J Pharmacol 2011;43:311-5.
51. Zuin R, Palamidese A, Negrin R, et al. High-dose N-acetylcysteine in patients with exacerbations of chronic obstructive pulmonary disease. Clin Drug Investig 2005;25:401-8.

52. Molnar Z, Szakmany T, Koszegi T, et al. Prophylactic $\mathrm{N}$-acetylcysteine decreases serum CRP but not PCT levels and microalbuminuria following Major abdominal surgery. A prospective, randomised, double-blinded, placebo-controlled clinical trial. Intensive Care Med 2003;29:749-55.

53. Saddadi F, Alatab S, Pasha F, et al. The effect of treatment with $\mathrm{N}$-acetylcysteine on the serum levels of $\mathrm{C}$-reactive protein and interleukin-6 in patients on hemodialysis. Saudi J Kidney Dis Transpl 2014;25:66-72.

54. Wild AC, Moinova HR, Mulcahy RT, et al. Regulation of gammaglutamylcysteine synthetase subunit gene expression by the transcription factor Nrf2. J Biol Chem 1999;274:33627-36.

55. Lee JS, Surh YJ. Nrf2 as a novel molecular target for chemoprevention. Cancer Lett 2005;224:171-84.

56. Breithaupt-Grögler K, Niebch G, Schneider E, et al. Doseproportionality of oral thioctic acid - coincidence of assessments via pooled plasma and individual data. Eur J Pharm Sci 1999;8:57-65.

57. Flier J, Van Muiswinkel FL, Jongenelen CA, et al. The neuroprotective antioxidant alpha-lipoic acid induces detoxication enzymes in cultured astroglial cells. Free Radic Res 2002;36:695-9.

58. Suh JH, Shenvi SV, Dixon BM, et al. Decline in transcriptional activity of Nrf2 causes age-related loss of glutathione synthesis, which is reversible with lipoic acid. Proc Natl Acad Sci U S A 2004;101:3381-6.

59. Papanas $\mathrm{N}$, Ziegler D. Efficacy of $\alpha$-lipoic acid in diabetic neuropathy. Expert Opin Pharmacother 2014;15:2721-31.

60. Monette JS, Gómez LA, Moreau RF, et al. (R)- $\alpha$-Lipoic acid treatment restores ceramide balance in aging rat cardiac mitochondria. Pharmacol Res 2011;63:23-9.

61. Tardif JC, Rhéaume E. Lipoic acid supplementation and endothelial function. Br J Pharmacol 2008;153:1587-8.

62. Hernandez OM, Discher DJ, Bishopric NH, et al. Rapid activation of neutral sphingomyelinase by hypoxia-reoxygenation of cardiac myocytes. Circ Res 2000;86:198-204.

63. Goldkorn T, Balaban N, Shannon M, et al. $\mathrm{H} 2 \mathrm{O} 2$ acts on cellular membranes to generate ceramide signaling and initiate apoptosis in tracheobronchial epithelial cells. J Cell Sci 1998;111:3209-20.

64. Castillo SS, Levy M, Thaikoottathil JV, et al. Reactive nitrogen and oxygen species activate different sphingomyelinases to induce apoptosis in airway epithelial cells. Exp Cell Res 2007;313:2680-6.

65. Jana A, Pahan K. Oxidative stress kills human primary oligodendrocytes via neutral sphingomyelinase: implications for multiple sclerosis. J Neuroimmune Pharmacol 2007;2:184-93.

66. Prochnicki T, Mangan MS, Latz E. Recent insights into the molecular mechanisms of the NLRP3 inflammasome activation. F1000Res 2016:5:5

67. Zhou R, Tardivel A, Thorens B, et al. Thioredoxin-interacting protein links oxidative stress to inflammasome activation. Nat Immunol 2010;11:136-40.

68. Oslowski CM, Hara T, O'Sullivan-Murphy B, et al. Thioredoxininteracting protein mediates ER stress-induced $\beta$ cell death through initiation of the inflammasome. Cell Metab 2012;16:265-73.

69. Mohamed IN, Hafez SS, Fairaq A, et al. Thioredoxin-interacting protein is required for endothelial NLRP3 inflammasome activation and cell death in a rat model of high-fat diet. Diabetologia 2014;57:413-23.

70. Abais JM, Zhang $\mathrm{C}$, Xia M, et al. NADPH oxidase-mediated triggering of inflammasome activation in mouse podocytes and glomeruli during hyperhomocysteinemia. Antioxid Redox Signal 2013;18:1537-48.

71. Gao P, He FF, Tang H, et al. NADPH oxidase-induced NALP3 inflammasome activation is driven by thioredoxin-interacting protein which contributes to podocyte injury in hyperglycemia. J Diabetes Res 2015;2015:1-12.

72. Müller-Calleja N, Köhler A, Siebald B, et al. Cofactor-independent antiphospholipid antibodies activate the NLRP3-inflammasome via endosomal NADPH-oxidase: implications for the antiphospholipid syndrome. Thromb Haemost 2015;113:1071-83.

73. Sun B, Wang X, Ji Z, et al. NADPH oxidase-dependent NLRP3 inflammasome activation and its important role in lung fibrosis by multiwalled carbon nanotubes. Small 2015;11:2087-97.

74. Wagner $\mathrm{AH}$, Köhler T, Rückschloss U, et al. Improvement of nitric oxide-dependent vasodilatation by HMG-CoA reductase inhibitors through attenuation of endothelial superoxide anion formation. Arterioscler Thromb Vasc Biol 2000;20:61-9.

75. Ishibashi Y, Matsui T, Takeuchi M, et al. Rosuvastatin blocks advanced glycation end products-elicited reduction of macrophage cholesterol efflux by suppressing NADPH oxidase activity via 
inhibition of geranylgeranylation of Rac-1. Horm Metab Res 2011;43:619-24

76. Erdös B, Snipes JA, Tulbert CD, et al. Rosuvastatin improves cerebrovascular function in Zucker obese rats by inhibiting $\mathrm{NAD}(\mathrm{P}) \mathrm{H}$ oxidase-dependent superoxide production. Am J Physiol Heart Circ Physiol 2006;290:H1264-H1270.

77. Lanone S, Bloc S, Foresti R, et al. Bilirubin decreases nos2 expression via inhibition of NAD(P)H oxidase: implications for protection against endotoxic shock in rats. Faseb $\mathrm{J}$ 2005;19:1890-2.

78. Matsumoto $\mathrm{H}$, Ishikawa $\mathrm{K}$, Itabe $\mathrm{H}$, et al. Carbon monoxide and bilirubin from heme oxygenase-1 suppresses reactive oxygen species generation and plasminogen activator inhibitor-1 induction. Mol Cell Biochem 2006;291:21-8.

79. Jiang F, Roberts SJ, Datla S, et al. NO modulates NADPH oxidase function via heme oxygenase-1 in human endothelial cells. Hypertension 2006:48:950-7.

80. McCarty MF. Clinical potential of Spirulina as a source of phycocyanobilin. J Med Food 2007;10:566-70.

81. Zheng J, Inoguchi T, Sasaki S, et al. Phycocyanin and phycocyanobilin from Spirulina platensis protect against diabetic nephropathy by inhibiting oxidative stress. Am J Physiol Regul Integr Comp Physiol 2013;304:R110-R120.
82. Adachi T, Takahara $\mathrm{K}$, Taneo J, et al. Particle size of latex beads dictates IL-1 $\beta$ production mechanism. PLoS One 2013;8:e68499.

83. Kim HY, Kim SJ, Lee SM, et al. Activation of NLRP3 and AIM2 inflammasomes in kupffer cells in hepatic ischemia/reperfusion. Febs J 2015;282:259-70.

84. Liu Y, Yao W, Xu J, et al. The anti-inflammatory effects of acetaminophen and $\mathrm{N}$-acetylcysteine through suppression of the NLRP3 inflammasome pathway in LPS-challenged piglet mononuclear phagocytes. Innate Immun 2015;21:587-97.

85. Li X, Liu S, Luo J, et al. Helicobacter pylori induces IL-1 $\beta$ and IL-18 production in human monocytic cell line through activation of NLRP3 inflammasome via ROS signaling pathway. Pathog Dis 2015;73.

86. Zhou Y, Zhao D, Yue R, et al. Inflammasomes-dependent regulation of IL-1 $\beta$ secretion induced by the virulent Mycobacterium bovis Beijing strain in THP-1 macrophages. Antonie Van Leeuwenhoek 2015;108:163-71.

87. Han S, Cai W, Yang X, et al. ROS-mediated NLRP3 inflammasome activity is essential for burn-induced acute lung injury. Mediators Inflamm 2015;2015:1-16.

88. Sun $\mathrm{X}$, Jiao $\mathrm{X}, \mathrm{Ma} \mathrm{Y}$, et al. Trimethylamine $\mathrm{N}$-oxide induces inflammation and endothelial dysfunction in human umbilical vein endothelial cells via activating ROS-TXNIP-NLRP3 inflammasome. Biochem Biophys Res Commun 2016;481:63-70. 